\title{
Xihuang Pill Inhibits The Development of DMBA Combined With Oestrogen- And Progesterone- Induced Precancerous Breast lesions In Rats By The PI3K/AKT/mTOR Signaling Pathway
}

Dehui Li (D258289951@qq.com)

Hebei University of Chinese Medicine https://orcid.org/0000-0001-7963-9410

Huan-fang Fan

Hebei University of Chinese Medicine

Na Guo

Hebei University of Chinese Medicine

Chun-xia Sun

Hebei University of Chinese Medicine

Jing-fei Dong

Hebei University of Chinese Medicine

Yi-fan Su

Hebei University of Chinese Medicine

Yi-ting Gu

Hebei University of Chinese Medicine

Jiao Liu

Hebei University of Chinese Medicine

\section{Research}

Keywords: Xihuang pill, Rat model, precancerous lesions of breast cancer, PI3K/AKT/mTOR, signaling pathway

Posted Date: September 2nd, 2021

DOl: https://doi.org/10.21203/rs.3.rs-753311/v1

License: (c) (1) This work is licensed under a Creative Commons Attribution 4.0 International License. Read Full License 


\section{Abstract}

Background:To study the inhibitory effect of Xihuang pill on the development of DMBA combined with oestrogen- and progesterone-induced breast precancerous lesions in rats by the PI3K/AKT/mTOR signaling pathway and to explore the effect of Xihuang pill in preventing and treating breast cancer.

Method: Establishment of a rat model of precancerous breast lesions with DMBA combined with oestrogen and progesterone sequential induction for 10 weeks. Xihuang pill was administered continuously by gavage for 4 weeks. Rat breast tissue was stained with haematoxylin-eosin (HE). The pathomorphological changes were observed with a light microscope. TUNEL staining was used to detect cell apoptosis in breast tissue. Western blotting was used to detect the protein expression of P-PI3K, PAKT (S473), P-AKT (T308), PTEN, P-tuberin/TSC2, P-tuberin (p-S939), p-mTOR, and P-4E-BP1 in breast tissues. qRT-PCR was used to detect the gene expression of PTEN mRNA and VEGF mRNA. Immunohistochemistry was used to detect the protein expression of P-S6, p-p70s6k and VEGF.

Result:Compared with the disease model group, the low-, middle- and high-dose Xihuang pill groups could significantly reduce the degree of breast pathology, and the number of apoptotic precancerous breast lesion cells increased with increasing Xihuang pill dose. The expression levels of P-PI3K, P-AKT (S473), PAKT (T308), p-mTOR, P-4E-BP1, p-S6, p-p70S6K, VEGF protein and VEGF mRNA dropped with increasing Xihuang pill dose. The expression levels of PTEN, P-tuberin/TSC2, P-tuberin ( $p$-S939) protein and PTEN mRNA increased with increasing Xihuang pill dose.

Conclusion:Xihuang pill can promote the apoptosis of precancerous breast lesion cells, reduce the proliferation of vascular endothelial cells, and then inhibit the progression of precancerous breast lesions. Its mechanism is probably associated with the regulation of the PI3K/AKT/mTOR pathway related protein expression.

\section{Introduction}

Cancer is a disease that seriously threatens human health worldwide. For women, the morbidity and mortality of breast cancer are rising year by year, which poses serious harm to women's health $[1,2]$. The genesis and progression of breast cancer is a process of "normal cells $\rightarrow$ simple hyperplasia $\rightarrow$ atypical hyperplasia $\rightarrow$ in situ carcinoma $\rightarrow$ invasive carcinoma" [3]. Precancerous lesions are the necessary stage for the genesis and progression of breast cancer, and they include simple hyperplasia, atypical hyperplasia and in situ carcinoma. Therefore, active intervention measures can block or even reverse the process of breast cancer [4]. Intervention for precancerous breast lesions and blocking their further development are the keys to preventing and curing breast cancer. Modern research methods of breast cancer treatment include targeted therapy, chemotherapy, endocrine therapy and surgery [5]. These methods have achieved good curative effects to cure breast cancer in the clinic, but there are many adverse reactions. Therefore, these methods are difficult for breast precancerous lesion patients to accept. Traditional Chinese medicine adheres to the academic thought of "preventive treatment of disease". In the period of precancerous lesions, traditional Chinese medicine can intervene to block the 
progression of breast cancer. Precancerous lesions of the breast belong to the category of "Ru $\mathrm{Pi}$ " of traditional Chinese medicine. Phlegm toxin and blood stasis are the core pathogeneses of its occurrence and development. The classic prescription Xihuang pill (XHP) has the effects of reducing phlegm and resolving masses, decreasing swelling and relieving pain, promoting blood circulation and removing blood stasis, and clearing heat and detoxification. Through clinical practice, XHP can be used to cure precancerous breast lesions and prevent breast cancer with distinct curative effects $[6,7]$. Our prophase research found that [8-10] XHP inhibited the activity of MCF-10AT precancerous breast lesions and induced apoptosis by suppressing mTOR and VEGF protein expression in the PI3K/AKT/mTOR signaling pathway and improved breast microcirculation and abnormal haemorheology in rats with 7,12dimethylbenzoanthracene (DMBA) combined with oestrogen- and progesterone-induced breast precancerous lesions. Breaking the balance between cell proliferation and apoptosis is the most important mechanism in breast cancer progression. The PI3K/AKT/mTOR signaling pathway is the main pathway that regulates the proliferation, growth, survival and apoptosis of breast cells. Its abnormal activation is very important for the occurrence and development of breast cancer. Therefore, inhibiting this signal transduction pathway has become the key to breast cancer target therapy and prevention of metastasis and recurrence. Based on this research, we hypothesized that the pharmacological mechanism by which XHP inhibits the development of precancerous breast lesions may be closely related to the PI3K/Akt/mTOR signaling pathway. For the purpose of proving this hypothesis, we established a rat model of precancerous breast lesions by sequential induction with DMBA combined with oestrogen and progesterone for 10 weeks in this study and then oral XHP for 4 weeks to study the effect of XHP on $\mathrm{PI} 3 \mathrm{~K} / \mathrm{AKT} / \mathrm{mTOR}$ signaling pathway induced breast cancer inhibition in rats with precancerous lesions and to analyse the mechanism of XHP prevention and treatment of breast cancer.

\section{Materials And Methods}

\subsection{Animals and Drugs}

Sixty SPF 6-week-old female Sprague-Dawley (SD) rats (weighing $180 \pm 20 \mathrm{~g}$ ) were purchased from Hebei Experimental Animal Center (Shijiazhuang, Hebei, China, licence number: 1705351). The animal experiment was approved by the medical ethics committee of Hebei University of Traditional Chinese Medicine and was in compliance with all regulatory guidelines. All methods were carried out in accordance with the ARRIVE guidelines (Animal Research: Reporting of In Vivo Experiments). All the rats were allowed food and water ad libitum. and they entered the experiment after 1 week of adaptive feeding. XHP (Zhejiang Tianyitang Pharmaceutical Co., Ltd. Division, lot No.: 1703011). DMBA (7,12Dimethylbenz[a]anthracene, TCl, CAS57-97-6). Oestradiol benzoate injection (Ningbo No. 2 Hormone Factory, lot No. 110252511). Tamoxifen citrate tablets (Yangzijiang Pharmaceutical Group Co., Ltd., lot No.: 17041311). Progesterone injection (Ningbo No. 2 Hormone Factory, lot No. 110251670).

Preparation of DMBA: accurately weigh DMBA, dissolve it in sesame oil at a ratio of $7 \mathrm{mg} \cdot \mathrm{ml}^{-1}$, and put it in a water bath at $60^{\circ} \mathrm{C}$ for dissolving by ultrasonic oscillation as a standby. 
Preparation of XHP aqueous solution: according to the needs of the experiment, soak the XHP in a little distilled water the day before the experiment, and the drug particles can be soaked exactly. On the day of the experiment, soft soaked XHP is crushed, and the concentrations are prepared with distilled water. XHP aqueous solutions of 270,550 , and $1370 \mathrm{mg} \cdot \mathrm{kg}^{-1}$ are reserved for use.

Tamoxifen aqueous solution preparation: According to the experimental needs, a tamoxifen aqueous solution of $4 \mathrm{~m} \cdot \mathrm{kg}^{-1}$ was prepared with distilled water.

\subsection{Model and Drug Use}

\subsubsection{Animal Model Establishment}

We established a rat model of precancerous breast lesions as previously reported in the literature [9-11]. On the $1^{\text {st }}$ day, DMBA dissolved in sesame oil was given to rats by gavage at a ratio of $1 \mathrm{ml} \cdot 100 \mathrm{~g}^{-1}$. From the second day, 5 days as a cycle (on days $1-3$, rats were injected with oestradiol benzoate at $0.5 \mathrm{mg} \cdot \mathrm{kg}^{-}$ ${ }^{1} \cdot d^{-1}$ into the inner side of the hind legs). On the $4^{\text {th }}$ day, rats were injected with progesterone at $4 \mathrm{mg}^{\circ} \mathrm{kg}^{-}$ ${ }^{1} \cdot d^{-1}$ into the inner side of the hind legs. Observation on day 5$)$. After 12 consecutive cycles, we established a rat model of precancerous breast lesions.

\subsubsection{Grouping and Administration Methods}

According to weight stratification and the random grouping method, 60 rats were divided into a normal control group $(n=10)$ and a disease model group $(n=50)$. The administration methods were as follows: Normal control group: After disposable gavage of $1 \mathrm{~mL} \cdot 100 \mathrm{~g}^{-1}$ sesame oil without DMBA, the rats were routinely fed. Disease model group: The model was reproduced in accordance with 2.2.1 Model Establishment method and fed routinely. After 10 weeks of successful modelling, rats in the disease model group were stochastically divided into 5 groups, with 10 rats in each group: disease model group, tamoxifen group and XHP low-, middle- and high-dose groups. The administration methods were as follows: Disease model group: fed routinely. In the tamoxifen group, $1 \mathrm{ml} \cdot 100 \mathrm{~g}^{-1}$ tamoxifen $\left(4 \mathrm{mg} \cdot \mathrm{kg}^{-1}\right)$ was given by gavage once a day for 28 days and the rats were fed routinely. XHP low-, middle- and highdose groups: Xihuang pills were given at low $\left(270 \mathrm{mg} \cdot \mathrm{kg}^{-1}\right)$, middle $\left(550 \mathrm{mg} \cdot \mathrm{kg}^{-1}\right)$ and high-dose (1370 $\left.\mathrm{mg} \cdot \mathrm{kg}^{-1}\right) 1 \mathrm{ml} \cdot 100 \mathrm{~g}^{-1}$ by gavage once a day for 28 days and fed routinely. At the end of the $14^{\text {th }}$ week of the animal experiment, the materials were collected. Before taking the material, the rats were fasted for 24 h, drank freely, and were euthanized by anaesthetic overdose of sodium pentobarbital $\left(200 \mathrm{mg} \cdot \mathrm{kg}^{-1}\right.$, i.p.). Six pairs of mammary glands and surrounding skin and subcutaneous tissue of the rat chest and abdomen were collected under sterile conditions, approximately $1.0 \mathrm{~cm} \times 1.0 \mathrm{~cm}$. Some tissue samples were fixed with $10 \%$ neutral buffered formalin and embedded in paraffin for $\mathrm{HE}$ and immunohistochemical and TUNEL staining. Some tissue samples were frozen in fluid nitrogen and kept at $-80^{\circ} \mathrm{C}$ for immunoblotting and later RT-qPCR. 


\subsection{HE Staining}

The tissue was embedded in paraffin, and the sections were deparaffinized. Then, haematoxylin stain, 10 minutes, tap water for 1 minute; $1 \%$ hydrochloric acid ethanol (70\% ethanol $(99 \mathrm{ml})+$ concentrated hydrochloric acid $(1 \mathrm{ml}))$, 20 seconds, tap water for 10 minutes; eosin stain, 10 minutes, tap water for 1 minute. Finally, the pathological changes in breast tissue were observed by transparent and sealed pieces.

\subsection{Immunohistochemical Detection}

Paraffin-embedded blocks were cut into 3- $\mu \mathrm{m}$ sections. The sections were then routinely dewaxed and rehydrated, followed by antigen retrieval for 5 min by sodium citrate buffer $(\mathrm{pH} 6.0)$ at $100^{\circ} \mathrm{C}$ and cooling naturally to room temperature. Then, each section was treated with $100 \mu \mathrm{L} 3 \% \mathrm{H}_{2} \mathrm{O}_{2}$ for 10 min to reduce endogenous peroxidase activity, washed using PBS (at pH 7.4, 3 times for $3 \mathrm{~min}$ ), and blocked with 100 $\mu \mathrm{L}$ of $2.5 \%$ normal goat serum for $30 \mathrm{~min}$ at room temperature prior to aspiration of the blocking solution. Then, $100 \mu \mathrm{L}$ of diluted primary antibody was added and incubated at room temperature for $1 \mathrm{~h}$, washed using PBS (at pH 7.4, 3 times for $3 \mathrm{~min}$ ), added to $100 \mu \mathrm{L}$ secondary antibody and incubated at room temperature for $30 \mathrm{~min}$, washed using PBS (at pH 7.4, 3 times for $3 \mathrm{~min}$ ), treated with $100 \mu \mathrm{L}$ diaminobenzidine (DAB) substrate-chromogen solution for $5 \mathrm{~min}$ and counterstained with Harris haematoxylin. Finally, the sections were differentiated in $1 \%$ acid alcohol, dehydrated and sealed with neutral gum, and then observed and photographed under a microscope. The above primary antibodies were as follows: phospho-S6 ribosomal protein (Ser235/236) XP® rabbit mAb (cat. no. 4858S; 1:400 dilution; CST); VEGF antibody (cat. no. NB100-664; 1:50 dilution; Novus); antiphospho-p70 S6 kinase (pThr389) antibody (cat. no. SAB4503957; 1:50 dilution; Sigma).

\subsection{TdT-mediated dUTP Nick End Labelling (TUNEL)}

First, paraffin-embedded breast tissue blocks were cut into 3- $\mu \mathrm{m}$ sections, and each section was stained, parched chip, dewaxed and rinsed with PBS. Then, $50 \mu \mathrm{L}$ TUNEL reaction mixed liquids (in situ cell death detection kit-POD, cat. no. 11684817910; Roche) was added to each section, and the reaction time was 1 $\mathrm{h}$ in a dark wet box at $37^{\circ} \mathrm{C}$, followed by rinsing with PBS ( $3 \mathrm{~min} \times 3$ times) protected from light. (After staining with TUNEL reaction mixed liquids, the tissue showed green fluorescence under a $488 \mathrm{~nm}$ wavelength light fluorescence microscope). PBS was removed, and 50 $\mathrm{LL}$ DAPI (cat. no. AR1177; BOSTER) was added to each section, incubated for $10 \mathrm{~min}$ at room temperature and rinsed 3 times in PBS, each time for $3 \mathrm{~min}$. (After DAPI staining, the tissue showed blue fluorescence under $405 \mathrm{~nm}$ wavelength light of fluorescence microscope, i.e., IF single staining). Finally, the fluorescent antiquencher (cat. no. P0126; Biyuntian, China) was added and observed after sealing. TUNEL-positive cells showed green labelling under a fluorescence microscope, while TUNEL-negative nuclei appeared blue with DAPI. 


\subsection{Reverse Transcription Real-Time qPCR (RT-qPCR)}

Breast tissues (20-50 mg) were split and centrifuged by RNA-Solv Reagent (Omega), total RNA was isolated, and the RNA concentration and quality were assessed at 260/280 nm and 260/230 nm using a UV-Visible spectrophotometer (756 MC, Shanghai Precision Scientific Instrument Corp., Shanghai, China). The ratios of OD260/OD280 were between 1.8 and 2.1. RNA concentration $(\mu \mathrm{g} / \mu \mathrm{l})=(\mathrm{OD} 260-\mathrm{OD} 320) \times$ dilution ratio $\times 0.04 . \mathrm{c})$. Total RNA $(2 \mu \mathrm{g})$ was reverse-transcribed using the PrimeScript ${ }^{\circledR} \mathrm{RT}$ reagent Kit with gDNA Eraser (Perfect Real Time; Takara, Dalian, China) according to the manufacturer's protocol. Then, quantitative real-time PCR (qRT-PCR) was performed using the Applied Biosystems 7500Fast RealTime PCR System and SYBR® Premix Ex Taq ${ }^{\text {TM }}$ (Tli RNaseH Plus; TaKaRa, Dalian, China). The following primers were used: GAPDH (internal control), forward primer sequence: $5^{\prime}-$

CAGGAAATGATGACCTCCTGAAC-3', reverse primer sequence: 5'-TGTTT TTGTAAGTATCTTGGTGCC-3', amplicon length was $80 \mathrm{bp}$; VEGF, forward primer sequence: 5'-GCAGATCATGCGGATCAAACC-3', reverse primer sequence: 5'-GCTCACAGTGAATGTGGTCACTTA-3', amplicon length was 136 bp; and PTEN, forward primer sequence: 5'-GCGTGCGGATAATGACAAGG-3', reverse primer sequence: 5'AGCCTCTGGATTTGATGGCTC-3', amplicon length was $157 \mathrm{bp}$. The PCR conditions were as follows. Initial denaturation at $95^{\circ} \mathrm{C}$ for $30 \mathrm{sec}$, followed by 40 cycles of $95^{\circ} \mathrm{C}$ for $5 \mathrm{sec}$ and $60^{\circ} \mathrm{C}$ for $30 \mathrm{sec}$. The specificity of the PCR product was confirmed by melting-curve analysis. Relative mRNA expression levels were calculated according to the $2^{-\Delta \Delta C t}$ method, and the formula was as follows[12, 13]: $\Delta C t=C T$ (target gene) - CT (internal reference); $\Delta \Delta \mathrm{CT}=\Delta \mathrm{Ct}$ experiment group $-\Delta \mathrm{Ct}$ control group.

\subsection{Western blot}

Rat breast tissue proteins were extracted with RIPA lysis buffer (R0020, Solarbio)), and the protein concentration was measured by a BCA protein assay kit (PC0020; Solarbio). Then, each lysed sample was mixed with SDS-PAGE loading buffer at a $4: 1$ ratio, boiled in a $100^{\circ} \mathrm{C}$ water bath for 5 min and centrifuged at 14,000 rpm for $5 \mathrm{~min}$. Twenty microlitres of the protein samples were subjected to SDSPAGE analysis and then transferred onto PVDF membranes (Millipore) at $100 \mathrm{~V}$ for 90 min. After transfer, membranes were blocked with $5 \%$ milk in TBST (T1081, Solarbio) for $1 \mathrm{~h}$ and then incubated with primary antibodies at $4^{\circ} \mathrm{C}$ overnight. The above primary antibodies were as follows: P-PI3K(SAB4503957, Absin), P-AKT(SER473)(4060S, CST), P-AKT(Thr308) (13038S, CST), P-mTOR(5536S, CST), PTEN(9188S, CST), P-tuberin/TSC2(3617S, CST), tuberin(p-s939)(ab52962, abcam), P-4E-BP1 (2855S,CST) and $\beta$-actin(Sc47778, Santa). All primary antibodies were used at a concentration of 1:1000. Then, the membranes were washed with TBST 3 times for 10 min each, incubated with secondary antibody (goat antirabbit IgG-HRP or goat antimouse IgG-HRP, Santa) at a 1:5000 dilution for $1 \mathrm{~h}$ at room temperature, and then washed with TBST 3 times for 10 min each. Then, the protein bands were detected using enhanced chemiluminescence (ECL).

\subsection{Statistical Methods}


All data are expressed as the mean \pm standard deviation and were analysed using the SPSS 20.0 statistical software package. Comparisons between groups were performed by one-way ANOVA. Differences in pathology data among the groups were analysed with the Wilcoxon rank-sum test. $P<0.05$ was statistically significant.

\section{Results}

\subsection{Effect of XHP on the Pathomorphology of Breast Tissue in Rats with Precancerous Breast Lesions}

The histological morphology and pathology results showed that there were no precancerous lesions or invasive cancer in the breast tissue of rats in the normal control group. However, the disease model group, tamoxifen group, XHP low-dose group, XHP middle-dose group and XHP high-dose group had various levels of precancerous lesions and invasive carcinomas (Figure 1). The Kruskal-Wallis $\mathrm{H}$ test showed that the differences between the groups were significant $\left(c^{2}=358.58, P=0.000\right.$.) and the degree of hyperplasia was the most serious in the disease model group (mean rank = 501.93). The results of the Mean-Whitney $U$ test showed that the degree of breast tissue hyperplasia in the disease model group was higher than the degree of breast tissue hyperplasia in the normal control group $(Z=14.529, P=0.000)$. The degree of breast tissue hyperplasia in the tamoxifen group and XHP low-, middle- and high-dose groups was lower than that in the disease model group $(P<0.05$ or $P<0.01)$ (Table 1$)$. XHP is suggested to be able to prevent and reverse the pathomorphological changes in breast tissue in rats with precancerous lesions induced by DMBA combined with oestrogen and progesterone.

Table 1 Comparison of the pathological changes of breast tissue in rats of each group

\subsection{Effect of XHP on Apoptosis of Breast Tissue Cells in Rats with Precancerous Breast Lesions}

The results of the TUNEL assay revealed that there was no apoptosis or little apoptosis in the normal control group (after DAPI staining, the nucleus showed blue fluorescence, and the apoptotic cells showed green fluorescence under a fluorescence microscope, that is, green fluorescence was TUNEL-positive cells). Compared with the normal control group, the apoptosis rate of the disease model group increased, and the difference was statistically significant $(P<0.05)$; Compared with the disease model group, tamoxifen group and XHP low-, middle- and high-dose groups significantly increased the apoptosis 


\begin{tabular}{|c|c|c|c|c|c|c|}
\hline Groups & $\begin{array}{l}\text { Dose } \\
\left(\mathrm{mg} \cdot \mathrm{kg}^{-1}\right)\end{array}$ & $\begin{array}{l}\text { Breast } \\
\text { number }\end{array}$ & $\begin{array}{l}\text { No } \\
\text { hyperplasia }\end{array}$ & $\begin{array}{l}\text { General } \\
\text { hyperplasia }\end{array}$ & $\begin{array}{l}\text { Precancerous } \\
\text { lesions }\end{array}$ & $\begin{array}{l}\text { Invasive } \\
\text { carcinomas }\end{array}$ \\
\hline $\begin{array}{l}\text { Normal } \\
\text { control }\end{array}$ & - & 120 & 110 & 10 & 0 & 0 \\
\hline $\begin{array}{l}\text { Disease } \\
\text { model }\end{array}$ & - & $120 * \star$ & 0 & 7 & 95 & 18 \\
\hline Tamoxifen & 4 & $120^{\# \#}$ & 11 & 46 & 61 & 2 \\
\hline $\begin{array}{l}\text { XHP low- } \\
\text { dose }\end{array}$ & 270 & $120^{\#}$ & 4 & 15 & 89 & 12 \\
\hline $\begin{array}{l}\text { XHP } \\
\text { middle- } \\
\text { dose }\end{array}$ & 550 & $120^{\# \#}$ & 10 & 28 & 75 & 7 \\
\hline $\begin{array}{l}\text { XHP high- } \\
\text { dose }\end{array}$ & 1370 & $120^{\# \#}$ & 9 & 44 & 62 & 5 \\
\hline $\begin{array}{l}\text { Note: comp } \\
{ }^{\#} P<0.05,{ }^{\#}\end{array}$ & $\begin{array}{l}\text { with the } \mathrm{r} \\
05 \text {. }\end{array}$ & mal con & group, $\star \star * P<$. & 1; compared & the disease $\mathrm{m}$ & del group, \\
\hline
\end{tabular}

of breast tissue, and the difference was statistically significant $(P<0.05)$, and the effect of the high-dose group of XHP was better than that of middle- and low-dose groups. These results suggested that XHP can induce the apoptosis of breast tissue cells in rats with precancerous breast lesions (Figure 2-3).

\subsection{Effect of XHP on the Protein Expression of P-PI3K, PTEN, P-AKT (S473) and P-AKT (T308) in Tissue Cells of Breast Precancerous Lesion Rats}

The protein levels of P-PI3K, PTEN, P-AKT (S473) and P-AKT (T308) were detected by Western blot analysis, and the results showed that compared with the normal control group, the expression of P-PI3K, P-AKT (S473) and P-AKT (T308) protein in the disease model group was significantly higher, while the expression of PTEN protein was significantly lower $(P<0.05)$. The XHP low-, middle- and high-dose groups had significantly lower expression of the P-PI3K, P-AKT (S473) and P-AKT (T308) proteins and higher expression of the PTEN protein than the disease model group $(P<0.05)$. Therefore, the effect of the XHP high-dose group was better than the effect of the middle- and low-dose groups (Figure 4). 


\subsection{Effect of XHP on the Protein Expression of P- tuberin/TSC2, P-tuberin (p-S939), p-mTOR and P-4E-BP1 in Tissue Cells of Rats with Precancerous Breast Lesions}

Western blotting was used to detect the protein expression levels of P-tuberin/TSC2, P-tuberin (p-S939), pmTOR and P-4E-BP1 in rat breast tissues. The results showed that compared with the normal control group, the protein expression of P-tuberin/TSC2 and P-tuberin (p-S939) in breast tissue cells was decreased, but the protein expression of p-mTOR and P-4E-BP1 was increased in the disease model group, and the difference was statistically significant $(P<0.05)$. Compared with the disease model group, the protein expression of P-tuberin/TSC2 and P-tuberin (p-S939) in the XHP low-, middle- and high-dose groups was significantly increased, while the protein expression of p-mTOR and P-4E-BP1 was decreased, and the difference was statistically significant $(P<0.05)$. In addition, the effect of the XHP high-dose group was better than the effect of the middle- and low-dose groups (Figure 5).

\subsection{Effect of XHP on the Protein Expression of p-S6, p- p70S6K, and VEGF in Tissue Cells of Rats with Precancerous Breast Lesions}

The protein expression of p-S6, p-p70S6K and VEGF was detected with immunohistochemistry in the breast tissue of rats in each group. The positive cell percentage was measured using ImageJ software. The results showed that in the normal control group, little or no p-S6, p-p70S6K or VEGF protein was expressed in breast tissue cells. Compared with the normal control group, the protein expression of p-S6, p-p70S6K and VEGF in breast tissue cells of the disease model group was increased, and the difference was statistically significant $(P<0.05)$. Compared with the disease model group, the protein expression of p-S6, p-p70S6K and VEGF in the XHP low-, middle- and high-dose groups was decreased, and the difference was statistically significant $(P<0.05)$. In addition, the effect of the XHP high-dose group was better than the effect of the middle- and low-dose groups (Figure 6-7).

\subsection{Effect of XHP on PTEN mRNA and VEGF mRNA Levels in Tissue Cells of Precancerous Breast Lesions in Rats}

Relative expression levels of PTEN mRNA and VEGF mRNA in each group were determined by qRT-PCR. PTEN mRNA in rats in the disease model group was significantly decreased compared with the PTEN mRNA in rats in the normal control group $(P<0.05)$. indicating that there was a deletion of PTEN mRNA in the breast tissue of rats with precancerous lesions induced by DMBA combined with oestrogen and progesterone. 
Compared with the disease model group, the level of PTEN mRNA expression was significantly increased in the XHP low-, middle- and high-dose groups $(P<0.05)$. These results suggested that XHP can upregulate the expression of PTEN mRNA or prevent the loss of PTEN mRNA in the breast tissue of rats with precancerous breast lesions induced by DMBA combined with oestrogen and progesterone (Figure 8).

The expression level of VEGF mRNA in the disease model group was significantly increased compared with the expression level of VEGF mRNA in the normal control group $(P<0.05)$, which suggested that the expression of VEGF mRNA in the breast tissue of rats with precancerous lesions induced by DMBA combined with oestrogen and progesterone was upregulated. The expression level of VEGF mRNA in the XHP low-, middle- and high-dose groups was significantly decreased compared with the expression level of VEGF mRNA in the disease model group $(P<0.05)$. XHP is suggested to be able to inhibit the protein synthesis of VEGF mRNA or downregulate the expression of VEGF mRNA in breast tissue of precancerous breast lesions in rats induced by DMBA combined with oestrogen and progesterone (Figure 8).

\section{Discussion}

Xihuang pill (XHP) is a famous patented Chinese medicine that has a therapeutic effect on tumours and was first recorded in the "waike zhengzhi quansheng ji" of the ancient Chinese Qing Dynasty. XHP consists of bezoars, musk, frankincense (vinegar) and myrrh (vinegar)[14]. XHP has the effects of promoting blood circulation and removing blood stasis, clearing heat and detoxification, reducing phlegm and resolving masses, decreasing swelling and relieving pain [15]. In recent years, with the rapid growth of integrated traditional Chinese/complementary medicine and modern medicine, the function of XHP in breast cancer progression has been most extensively studied. Clinical studies clearly show that XHP combined with chemotherapy, radiotherapy or endocrine therapy could significantly improve the clinical efficacy, KPS, and immune function and reduce the toxicity of chemotherapy or radiotherapy in breast cancer patients $[14,16,17]$. Animal experiments have also confirmed that XHP may inhibit breast cancer through the downregulation of the oestrogen receptor (ER) and expression of the progesterone receptor (PR), inhibition of Bc1-2 expression, and increase in p53 gene expression and IL-2, IFN- $y$, CD $3+, C D 4^{+}$and B7-1 levels $[17,18]$. XHP can inhibit the growth of breast cancer in 4T1 mice through upregulation of MEKK1, SEK1, JNK1, and AP-1 expression in Tregs, promoting Treg cell apoptosis in the tumour immune microenvironment [7]. In vitro experiments showed that XHP inhibited proliferation and migration but advanced the apoptosis of MCF-7, Hs578T and MDA-MB435 breast cancer cell lines and MCF-10AT precancerous breast lesions.

Its mechanisms might be associated with regulating the protein and gene expression of Cyclin A, CDK2, Bcl-2, Bax, mTOR and VEGF $[8,19,20]$. Based on our research [8-10, 17], we hypothesized that the pharmacological mechanism by which XHP inhibits the development of precancerous breast lesions could be closely interrelated with the PI3K/Akt/mTOR signaling pathway. 
The current study used a model of 7,12-dimethylbenz[a]anthracene (DMBA) in combination with oestrogen- and progesterone-induced precancerous breast lesions in rats. After confirming that the model was successfully established, XHP was administered for treatment. Subsequently, the specific molecular mechanisms of XHP were investigated. The pathomorphological analysis revealed that the Xihuang pill could block and reverse the histopathological changes in breast tissue induced by DMBA combined with oestrogen and progestogen. Moreover, the immunofluorescence TUNEL staining assay of breast tissue cells of breast precancerous lesions rats showed that the number of TUNEL-positive cells in the XHP group increased compared with the normal control group. In addition, we found a greater number of apoptotic cells in the XHP high-dose group than in the middle-dose and low-dose groups. These findings revealed that XHP amplified apoptosis in a dose-dependent manner. The imbalance between the proliferation and apoptosis of cells was closely associated with breast tumourigenesis and development. The PI3K/Akt/mTOR pathway is an important intracellular signaling transduction pathway that participates in cell multiplication, differentiation, apoptosis, cycle progression, motility, tumourigenesis, tumour growth and angiogenesis and plays a major role in both the occurrence and progression of breast cancer $[21,22]$. Therefore, inhibition of the PI3K/Akt/mTOR pathway is critical for breast cancer therapy. This signaling pathway involves four key molecules, PI3K, PTEN, Akt and mTOR [23]. PI3K consists of a regulatory subunit (p85) and a catalytic subunit (p110), and the activation of PI3K depends upon the activation of the p85 subunit. Once PI3K is activated, its catalytic subunit activates AKT through phosphorylation of AKT and continuously activates mTOR through phosphorylation of mTOR [24]. AKT has two important phosphorylation sites: Thr308 and Ser473. The phosphorylation of serine 473 is necessary for the complete activation of AKT [25]. mTOR is a key downstream mediator in the $\mathrm{PI} 3 \mathrm{~K} / \mathrm{Akt} / \mathrm{mTOR}$ signaling pathway that plays a key role in regulating cell growth and hyperplasia during breast cancer development [26]. PTEN is a negative regulator in the PI3K-Akt-mTOR signaling pathway and can dephosphorylate PI3K to downregulate the activation of the PI3K-Akt-mTOR pathway [27]. In this study, we found that XHP could significantly reduce the protein expression of P-PI3K, P-AKT (S473) and PAKT (T308) in precancerous breast lesion cells, and the higher the dose of XHP, the lower the expression of the three proteins, so there was a negative correlation; XHP could increase the protein expression of PTEN, which was positively related to the dose of XHP.

TSC2 is a potent mTOR suppressor, and phosphorylation of TSC2 disturbs the formation of the TSC1TSC2 complex, which negatively regulates MTOR activity [28]. Wen G Jiang et al. [29] researched the expression of the TSC gene in breast cancer cells or tissues and found that TSC was strongly positively expressed in normal breast epithelial cells. In invasive tumour tissues, the gene expression was decreased, and the transcription level of TSC2 in normal tissues was apparently higher than the transcription level of TSC2 in tumours. Activation of mTOR promotes the phosphorylation of its downstream effectors, including phosphorylation of elF4E binding protein 1 (4EBP1) and activation of p70 ribosomal S6 protein kinase (p70S6K), which phosphorylates S6 ribosomal protein and induces cell proliferation, angiogenesis and metastasis [30]. Studies have shown that when elF4E increases, the protein expression of VEGF also increases accordingly. Studies have shown that 4EBP1 could upregulate the translation of VEGF mRNA and promote breast cancer angiogenesis [31]. Shao Bo et al. [32] studied 
the expression of $\mathrm{p}-\mathrm{S} 6$ in breast tumour tissues, adjacent nontumourous tissues and benign breast lesion tissues by immunohistochemistry and discovered that $\mathrm{p}-\mathrm{S} 6$ expression was upregulated in breast tumours and related to the occurrence and progression of breast cancer. Lao Hai li et al. [33] studied the expression level of the mTOR/p70S6K signaling pathway in breast cancer, and the investigation suggested that the mTOR/P70S6K signaling pathway is specifically activated in breast cancer and might play an important role in the pathogenesis of breast cancer. Elevated expression of VEGF is a feature of invasive breast cancer [34]. In this project, upstream regulatory factors (P-tuberin/TSC2 and P-tuberin ( $p$ S939)), downstream regulatory factors (P-4E-BP1, p-S6, p-p70S6K, VEGF) and p-mTOR proteins related to $\mathrm{PI} 3 \mathrm{~K} / \mathrm{Akt} / \mathrm{mTOR}$ were analysed. Western blot assays showed that compared with the disease model group, the expression of P-tuberin/TSC2 and P-tuberin (p-S939) protein was increased in the XHP low-, middle- and high-dose groups, while the expression of p-mTOR and P-4E-BP1 protein was decreased. The effect of the high-dose XHP group was better than that of the middle- and low-dose groups.

Immunohistochemistry results showed that the protein expression of p-S6, p-p70S6K and VEGF was significantly decreased, and the dose of XHP was negatively correlated with the protein expression compared with the disease model group, strongly suggesting that XHP can upregulate the upstream negative regulatory factors of mTOR, such as P-tuberin/TSC2 and P-tuberin ( $p$-S939), and downregulate downstream regulatory factors, such as P-4E-BP1, p-S6, p-p70S6K, and VEGF, which can block the $\mathrm{PI} 3 \mathrm{~K} / \mathrm{Akt} / \mathrm{mTOR}$ signaling pathway, thereby effectively inhibiting precancerous breast lesions.

qRT-PCR was used to analyse the expression of PTEN mRNA and VEGF mRNA in the breast tissue of rats. Compared with the disease model group, the expression levels of PTEN mRNA in each dose group of XHP were significantly increased, while the expression of VEGF mRNA was decreased. These results suggest that XHP can prevent the loss of PTEN mRNA or upregulate the expression of PTEN mRNA in the breast tissue of rats with precancerous breast lesions. However, the decrease in VEGF mRNA gene expression indicates that XHP can inhibit the transcription of VEGF mRNA or downregulate the expression level of VEGF mRNA in breast tissue of precancerous breast lesion rats. The above results were consistent with the results for PTEN by Western blot and VEGF by immunohistochemistry. Therefore, the PTEN and VEGF genes are relatively antagonistic in the process of transcription and protein synthesis. PTEN gene activation can inhibit VEGF by interrupting the PI3K/AKT signaling pathway to affect the synthesis of angiogenic factors and then inhibit neovascularization in breast cancer.

\section{Conclusion}

In summary, we have proposed a new mechanism by which XHP inhibits the progression of precancerous breast lesions in rats induced by DMBA combined with oestrogen and progesterone. The PI3K/Akt/mTOR signaling pathways were involved in this process. Intervention on breast precancerous lesions rats with XHP inhibits proliferation and induces apoptosis through inhibiting PI3K/AKT/mTOR signaling by upregulating the expression of proteins PTEN, P-tuberin/TSC2, P-tuberin ( $\mathrm{p}$-S939) and PTEN mRNA and downregulating the expression of proteins P-PI3K, P-AKT (S473), P-AKT (T308), p-mTOR, P-4E-BP1, p-S6, p-p70S6K, VEGF and VEGF mRNA, suggesting XHP may become a promising antitumour drug by directly regulating the $\mathrm{PI} 3 \mathrm{~K} / \mathrm{AKT} / \mathrm{mTOR}$ pathway in prebreast cancer. 


\section{Abbreviations}

DAB,diaminobenzidine; DMBA,dimethylbenzoanthracene; ER,oestrogen receptor; $\mathrm{HE}$,haematoxylin-eosin; PR,progesterone receptor; qRT-PCR,quantitative real-time PCR; SD,Sprague-Dawley; XHP,Xihuang pill

\section{Declarations}

\section{Ethics approval and consent to participate:}

The animal experiment was approved by the medical ethics committee of Hebei University of Traditional Chinese Medicine and was in compliance with all regulatory guidelines. All methods were carried out in accordance with the ARRIVE guidelines (Animal Research: Reporting of In Vivo Experiments).

\section{Consent for publication:}

Not applicable.

\section{Availability of data and materials:}

All data generated or analysed during this study are included in this published article.

\section{Competing interests:}

The authors declare that they have no competing interests

Funding:This research was financially supported by grants from the Youth Program of National Natural Science Foundation of China (Grants No. 81603412), Key r\&d Projects of Hebei Province (Grants No. 18277731D), Research Project of Administration of Traditional Chinese Medicine of Hebei Province (Grants No. 2017163, 2019008, 2020014), General Projects for Improving Scientific Research Capacity of Hebei University of TCM (Grants No. KTY2019009), Hebei Key Laboratory of Chinese Medicine Research on Cardio-Cerebrovascular Disease, Hebei Key Laboratory of Integrative Medicine on Liver-kidney Patterns (Grants No. A201902), Hebei Province "three three three talent project" funded project (Grants No. A202002008).

\section{Authors' contributions:}

Conceived and designed the experiments: D. H. Li. Performed the experiments:D. H. Li, H. F. Fan, N. Guo, C. X. Sun, J. F. Dong. Analysed the data: Y. F. Su, Y. T. Gu, J. Liu. Wrote the paper: H. F. Fan, D. H. Li. 


\section{Acknowledgements:}

Thank the institutions that provided financial support(the Youth Program of National Natural Science Foundation of China (Grants No. 81603412), Key r\&d Projects of Hebei Province (Grants No. 18277731D), Research Project of Administration of Traditional Chinese Medicine of Hebei Province (Grants No. 2017163, 2019008, 2020014), General Projects for Improving Scientific Research Capacity of Hebei University of TCM (Grants No. KTY2019009), Hebei Key Laboratory of Chinese Medicine Research on Cardio-Cerebrovascular Disease, Hebei Key Laboratory of Integrative Medicine on Liver-kidney Patterns (Grants No. A201902), Hebei Province "three three three talent project" funded project (Grants No. A202002008).

\section{References}

1. Siegel RL, Miller KD, Jemal A. Cancer statistics, 2020. CA Cancer J Clin. 2020;70(1):7-30. doi:10.3322/caac.21590.

2. Bray F, Ferlay J, Soerjomataram I, Siegel RL, Torre LA, Jemal A. Global cancer statistics 2018: GLOBOCAN estimates of incidence and mortality worldwide for 36 cancers in 185 countries. CA Cancer J Clin. 2018;68(6):394-424. doi:10.3322/caac.21492.

3. Han B, Du Y, Fu T, Fan ZM, Xu SP, Hu CX, et al. Differences and Relationships Between Normal and Atypical Ductal Hyperplasia, Ductal Carcinoma In Situ, and Invasive Ductal Carcinoma Tissues in the Breast Based on Raman Spectroscopy. Appl Spectrosc. 2017;71(2):300-7. doi:10.1177/0003702816681009.

4. Danforth DN. Molecular profile of atypical hyperplasia of the breast. Breast Cancer Res Treat. 2018;167(1):9-29. doi:10.1007/s10549-017-4488-x.

5. Waks AG, Winer EP. Breast Cancer Treatment. JAMA. 2019;321(3):316. doi:10.1001/jama.2018.20751.

6. Yu D, An GY. (2017). Clinical Effects of Xihuang Pill Combined with Chemotherapy in Patients with Advanced Colorectal Cancer. Evid Based Complement Alternat Med. 2017, 5936086. doi:10.1155/2017/5936086.

7. Su L, Jiang YM, Xu Y, Li XY, Gao WB, Xu CW, et al. Xihuang pill promotes apoptosis of Treg cells in the tumor microenvironment in 4T1 mouse breast cancer by upregulating MEKK1/SEK1/JNK1/AP-1 pathway. Biomed Pharmacother. 2018;102:1111-9. doi:10.1016/j.biopha.2018.03.063.

8. Li DH, Fan HF, Sun CX, Wang X. Effects of liquid extract of Xihuang pills on mTOR and VEGF expression in precancerous cells of human breast cancer. Hunan Journal of Traditional Chinese Medicine. 2017;33(6):145-8. doi:10.16808/j.cnki.issn1003-7705.2017.06.068.

9. Li DH, Su YF, Fan HF, Sun CX, Han CH, Ma P, et al. (2020) Effect of Xihuang Pill on microcirculation in DMBA combined estrogen and progesterone induced breast precancerous lesions rats. in 2nd International Conference on Environmental Prevention and Pollution Control Technologies, EPPCT 
2020, January 10, 2020 - January 12, 2020, Sanya, China: IOP Publishing Ltd. doi:10.1088/17551315/474/5/052053.

10. Li DH, Su YF, Fan HF, Sun CX, Han CH, Ma P, et al. Effect of Xihuang Pill on Hemorheological Properties in DMBA Combined Estrogen and Progesterone Induced Breast Precancerous Lesions Rats. Basic Clinical Pharmacology Toxicology. 2020;127:14-5.

11. Zhang GJ, Jiang XF, Liu YS, Hao XQ, Wang YR, Yan XX, et al. (2019). Therapeutic Efficiency of an External Chinese Herbal Formula of Mammary Precancerous Lesions by BATMAN-TCM Online Bioinformatics Analysis Tool and Experimental Validation. Evid Based Complement Alternat Med. 2019, 2795010. doi:10.1155/2019/2795010.

12. Wang WY, Cao YX, Zhou X, Wei B, Zhan L, Fu LT, et al. HMGA2 gene silencing reduces epithelialmesenchymal transition and lymph node metastasis in cervical cancer through inhibiting the ATR/Chk1 signaling pathway. Am J Transl Res. 2018;10(10):3036-52.

13. Cheng JZ, Chen JJ, Zhao Y, Yang JP, Xue K, Wang ZJ. MicroRNA-761 suppresses remodeling of nasal mucosa and epithelial-mesenchymal transition in mice with chronic rhinosinusitis through LCN2. Stem Cell Res Ther. 2020;11(1):151. doi:10.1186/s13287-020-01598-7.

14. Guo Q, Lin JY, Liu R, Gao YB, He SL, Xu XY, et al. (2015). Review on the Applications and Molecular Mechanisms of Xihuang Pill in Tumor Treatment. Evid Based Complement Alternat Med. 2015, 854307. doi:10.1155/2015/854307.

15. Pei XH, Deng WF. Realization on Toxin and Blood Stasis Intertwining Syndrome of Precancerosis in Breast Cancer. China Journal of Chinese Medicine. 2010;25(02):200-1. doi:10.16368/j.issn.16748999.2010.02.089.

16. Mao D, Feng L, Huang S, Zhang S, Peng W, Zhang S. (2019). Meta-Analysis of Xihuang Pill Efficacy When Combined with Chemotherapy for Treatment of Breast Cancer. Evid Based Complement Alternat Med. 2019, 3502460. doi:10.1155/2019/3502460.

17. Li DH, Fan HF, Sun CX. Research Progress of the Xihuang Pill in Breast Cancer. Lishizhen Medicine Materia Medica Research. 2016;27(9):2247-8.

18. Sao M, Zhou TC, Yin ZX, Wu G, Wang QR. Anticancer effects and clinical application of Xihuang pill:research advances. Journal of International Pharmaceutical Research. 2017;44(6):504-9. doi:10.13220/j.cnki.jipr.2017.06.007.

19. Zheng WX, Han SY, Jiang ST, Pang LN, Li XH, Liu XJ, et al. Multiple effects of Xihuang pill aqueous extract on the Hs578T triple-negative breast cancer cell line. Biomed Rep. 2016;5(5):559-66. doi:10.3892/br.2016.769.

20. He LJ, Li JS, Chen X, Zhang HT, Zhu XG, Zhang XD, et al. Effect of serum containing Xihuang pill on proliferation of human breast cancer cell line MDA-MB-435 and MCF-7 Cells. China Journal of Chinese Materia Medica. 2018;43(13):2784-8. doi:10.19540/j.cnki.cjcmm.20180408.001.

21. Kenna MM, McGarrigle S, Pidgeon GP. The next generation of PI3K-Akt-mTOR pathway inhibitors in breast cancer cohorts. Biochimica et biophysica acta Reviews on cancer. 2018;1870(2):185-97. doi:10.1016/j.bbcan.2018.08.001. 
22. Yang H, Guan LY, Li S, Jiang Y, Xiong NY, Li L, et al. Mechanosensitive caveolin-1 activation-induced $\mathrm{PISK} / \mathrm{Akt} / \mathrm{mTOR}$ signaling pathway promotes breast cancer motility, invadopodia formation and metastasis in vivo. Oncotarget. 2016;7(13):16227-47. doi:10.18632/oncotarget.7583.

23. Yu G, Huang B, Chen G, Mi Y. Phosphatidylethanolamine-binding protein 4 promotes lung cancer cells proliferation and invasion via PI3K/Akt/mTOR axis. J Thorac Dis. 2015;7(10):1806-16. doi:10.3978/j.issn.2072-1439.2015.10.17.

24. Liu YP, Li L, Xu L, Dai EN, Chen WD. Cantharidin suppresses cell growth and migration, and activates autophagy in human non-small cell lung cancer cells. Oncol Lett. 2018;15(5):6527-32. doi:10.3892/ol.2018.8141.

25. Wen NY, Guo BF, Zheng HW, Xu LB, Liang H, Wang Q, et al. Bromodomain inhibitor jq1 induces cell cycle arrest and apoptosis of glioma stem cells through the VEGF/PI3K/AKT signaling pathwa. Int J Oncol. 2019;55(4):879-95. doi:10.3892/ijo.2019.4863.

26. Kanhaiya K, Rogojin V, Kazemi K, Czeizler E, Petre I. NetControl4BioMed: a pipeline for biomedical data acquisition and analysis of network controllability. BMC Bioinformatics. 2018;19(7):185. doi:10.1186/s12859-018-2177-3.

27. Zhou JJ, Cheng H, Wang ZJ, Chen H, Suo CJ, Zhang HC, et al. Bortezomib attenuates renal interstitial fibrosis in kidney transplantation via regulating the EMT induced by TNF-a-Smurf1-Akt-mTORP70S6K pathway. J Cell Mol Med. 2019;23(8):5390-402. doi:10.1111/jcmm.14420.

28. Hou HH, Cheng SL, Chung KP, Kuo MYP, Yeh CC, Chang BE, et al. Elastase induces lung epithelial cell autophagy through placental growth factor: a new insight of emphysema pathogenesis. Autophagy. 2014;10(9):1509-21. doi:10.4161/auto.29190.

29. Wen GJ, Julian S, Tracey AM, Lisa LJ, Gareth W, Anthony DJ, et al. Tuberin and hamartin are aberrantly expressed and linked to clinical outcome in human breast cancer: the role of promoter methylation of TSC genes. European journal of cancer (Oxford England: 1990). 2005;41(11):162836. doi:10.1016/j.ejca.2005.03.023.

30. Chen W, Lv LW, Nong ZH, Chen XY, Pan XR, Chen XX. Hyperbaric oxygen protects against myocardial ischemia-reperfusion injury through inhibiting mitochondria dysfunction and autophagy. Mol Med Rep. 2020;22(5):4254-64. doi:10.3892/mmr.2020.11497.

31. Kleiner HE, Krishnan P, Tubbs J, Smith M, Meschonat C, Shi R, et al. Tissue microarray analysis of elF4E and its downstream effector proteins in human breast cancer. J Exp Clin Cancer Res. 2009;28:5. doi:10.1186/1756-9966-28-5.

32. Sao B, Wu ZS, Wu Q. Expression and significance of LAT1 and p-s6 breast cancer. Chinese Journal of Clinical Experimental Pathology. 2018;34(1):7-11.

33. Lao HL, Li X, Wang HZ, Li YH, Wang JS. Expression and clinical significance of mTOR/p70S6K signaling pathway in breast carcinoma. China Clinical Practical Medicine. 2016;7(2):50-3.

34. Du Manoir S, Qrsetti B, Rui BG, Nguyen TT, Lasorsa L, Boissiere F, et al. Breast tumor PDXs are genetically plastic and correspond to a subset of aggressive cancers prone to relapse. Mol Oncol. 2014;8(2):431-43. doi:10.1016/j.molonc.2013.11.010. 


\section{Figures}

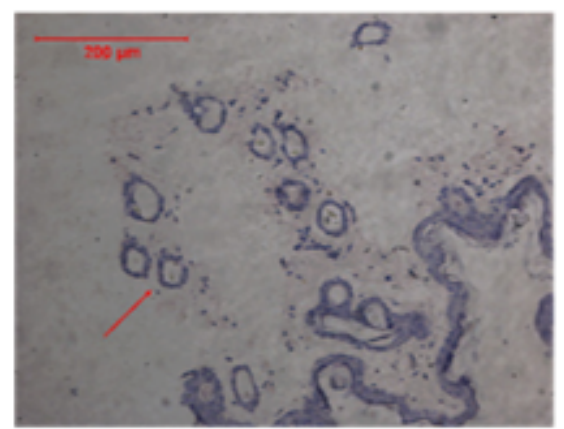

Normal control

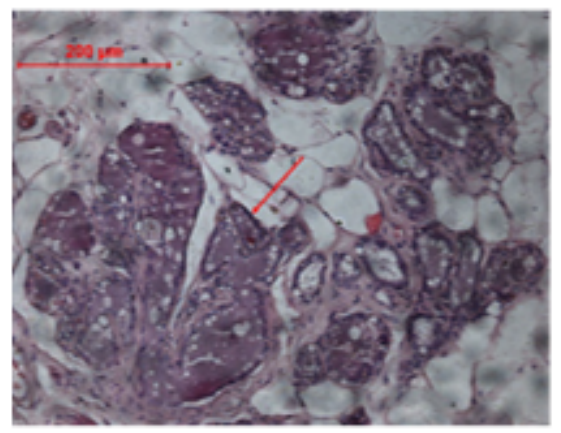

XHP low-dose

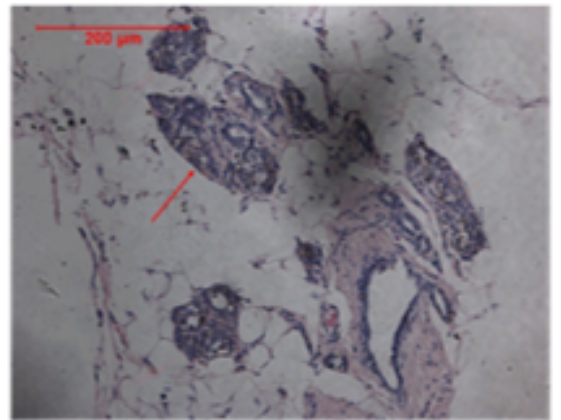

Disease model

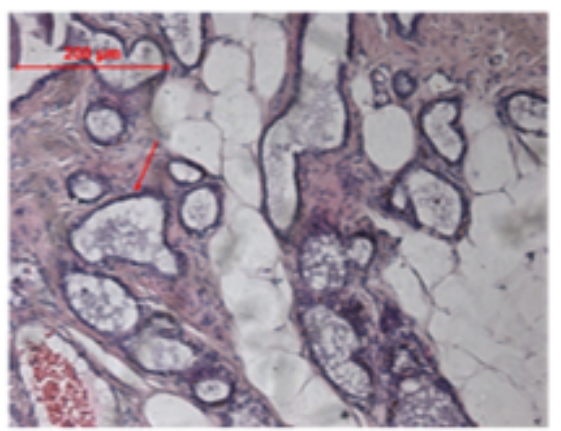

XHP middle-dose

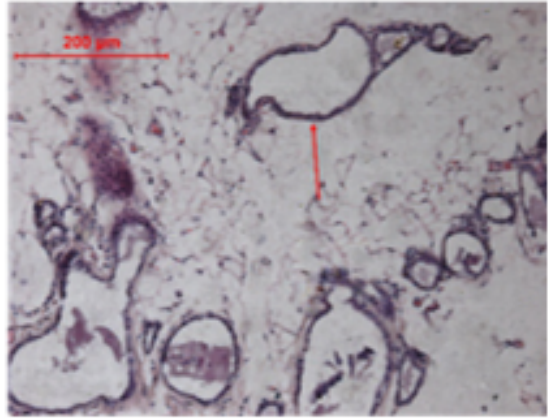

Tamoxifen

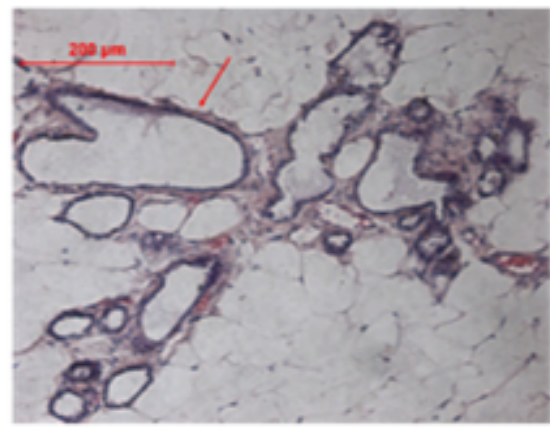

XHP high-dose

Figure 1

Histopathological changes in breast tissue in rats of each group (HE staining, $\times 100)$ 


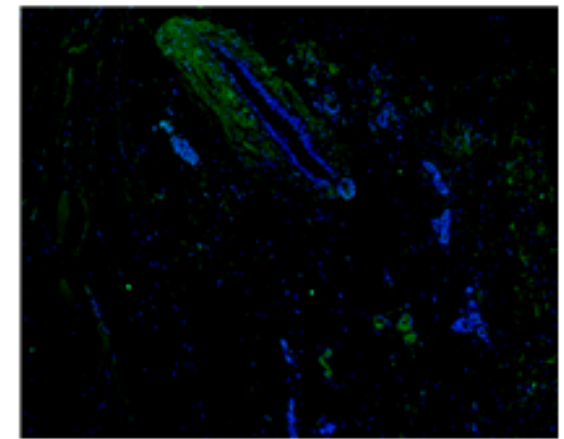

Norm al control

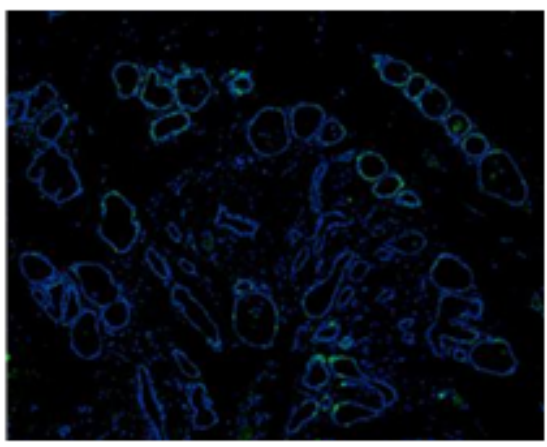

XHP low-dose

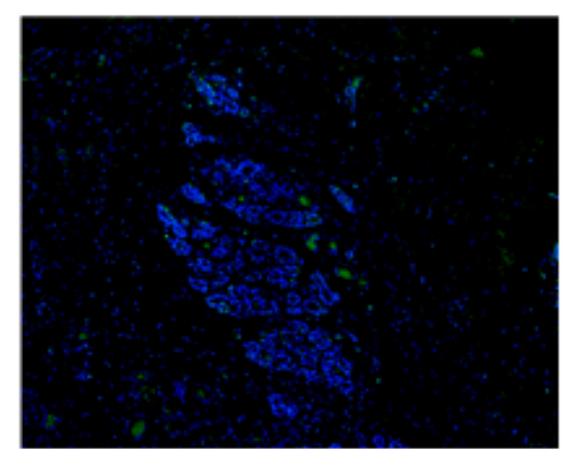

Disease model

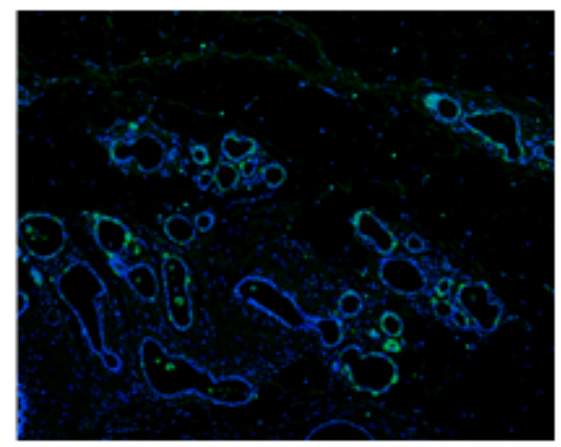

XHP middle-dose

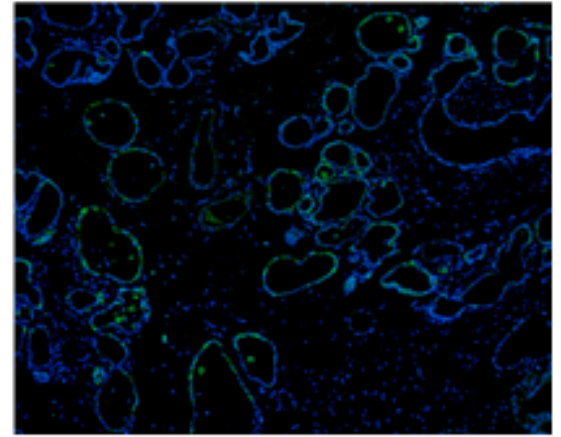

Tamoxifen

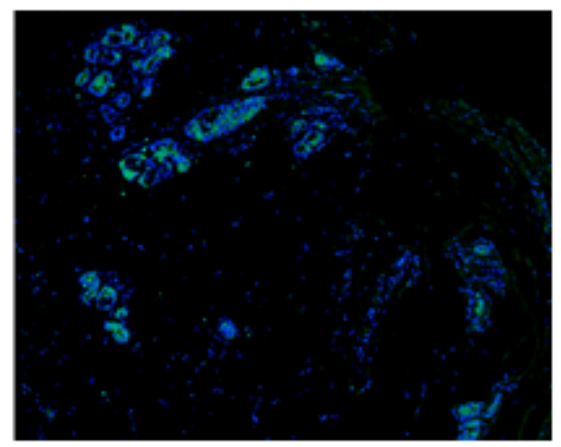

XHP high-dose

Figure 2

Apoptosis of breast tissue of rats in each group (TUNEL, $\times 100$ ) 


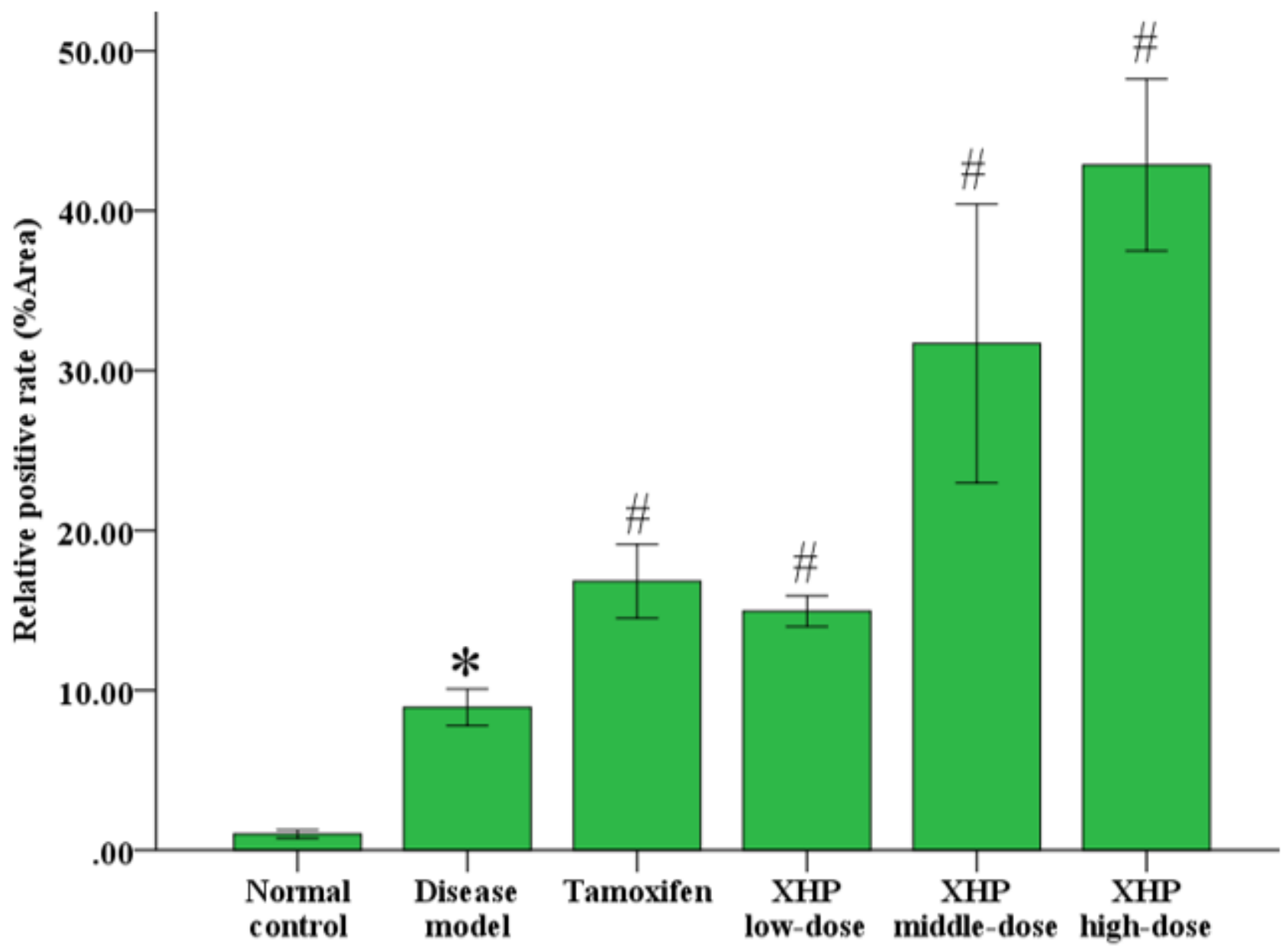

Figure 3

Relative changes in apoptosis in breast tissue from rats in each group. compared with the normal control group, ${ }^{*}<0.05$; compared with the disease model group, $\# P<0.05$. ( $n=10$ in each group).

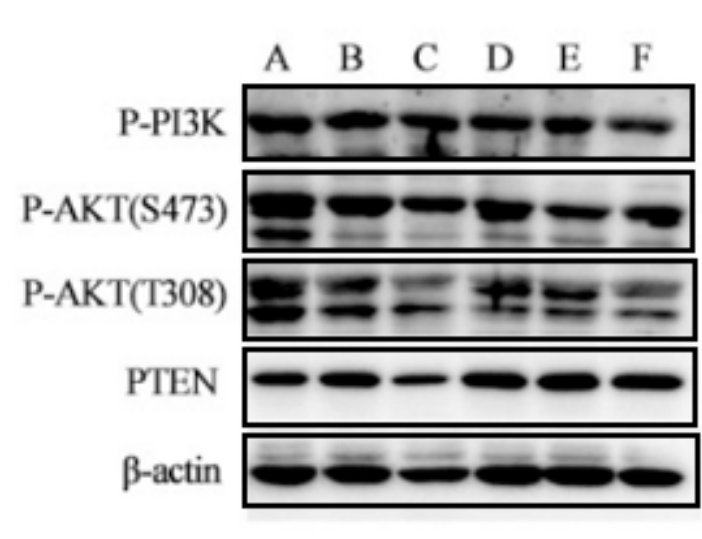

(A) Normal control group. (B) Disease model group. (C) Tamoxifen group.

(D) XHP low-dose group. (E) XHP middle-dose group. (F) XHP high-dose group.

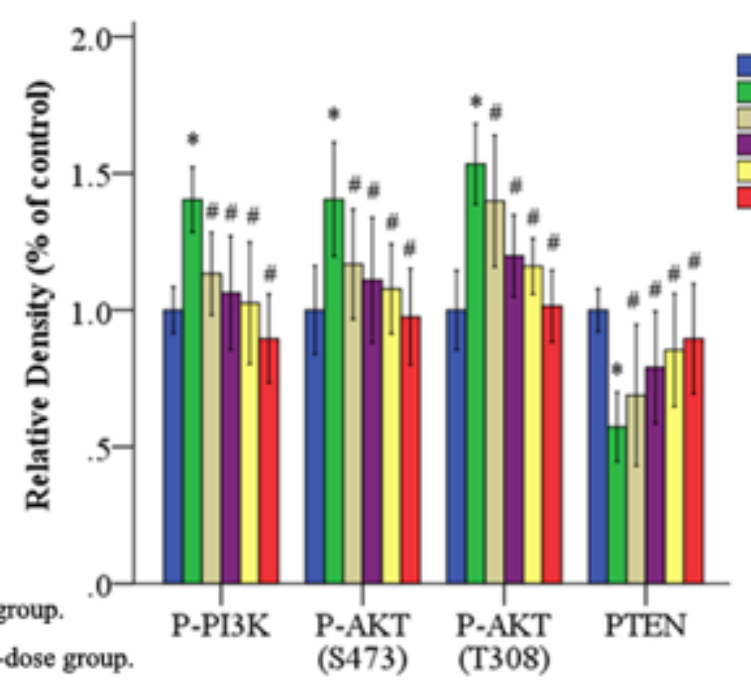

groups

Normal control

Disease model

Tramoxafen

XHP low-dose

XHP middle-dose

XHP ligh-dose 
Figure 4

Expression of P-PI3K, P-AKT (S473), P-AKT (T308) and PTEN protein in breast tissue of rats in each group. Compared with the normal control group, ${ }^{*} \mathrm{P}<0.05$; compared with the disease model group, $\# P<0.05$. ( $n=10$ in each group).

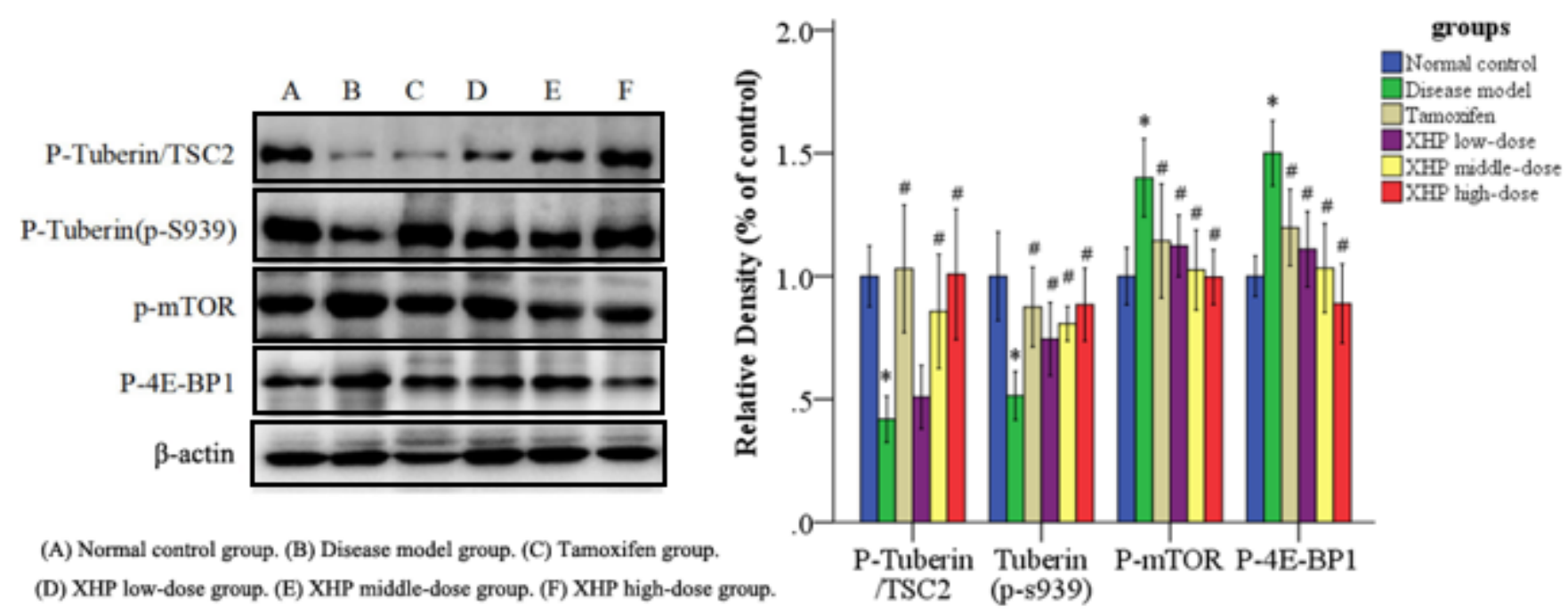

\section{Figure 5}

Protein expression of P-tuberin/TSC2, P-tuberin (p-S939), p-mTOR and P-4E-BP1 in the breast tissue of rats in each group. Compared with the normal control group, ${ }^{*}<0.05$; compared with the disease model group, $\# P<0.05$. $(n=10$ in each group).

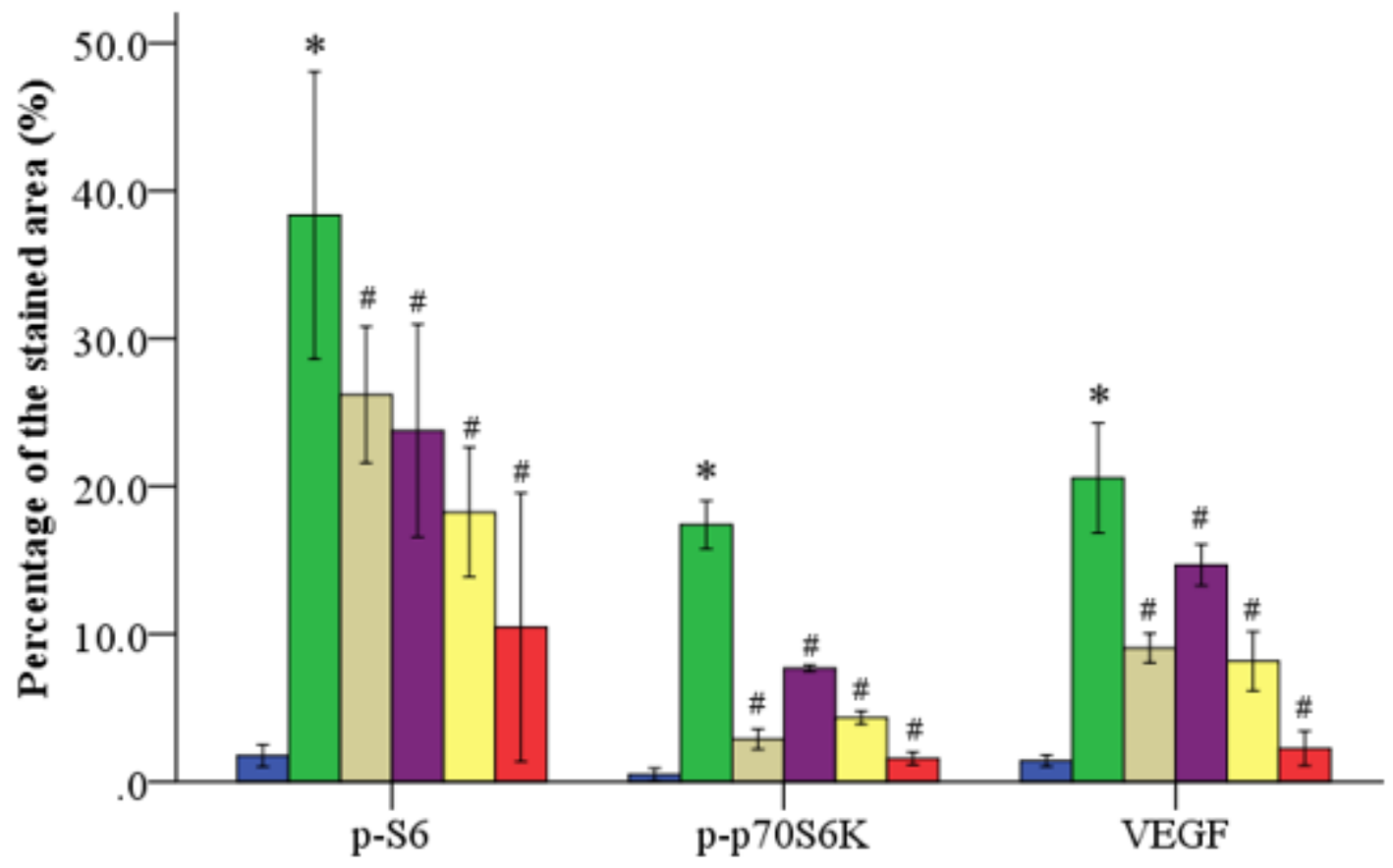

Figure 6 
Protein expression of p-S6, p-p70S6K and VEGF in the breast tissue of rats in each group. Compared with the normal control group, ${ }^{*}<<0.05$; compared with the disease model group, $\# P<0.05$. $(n=10$ in each group).

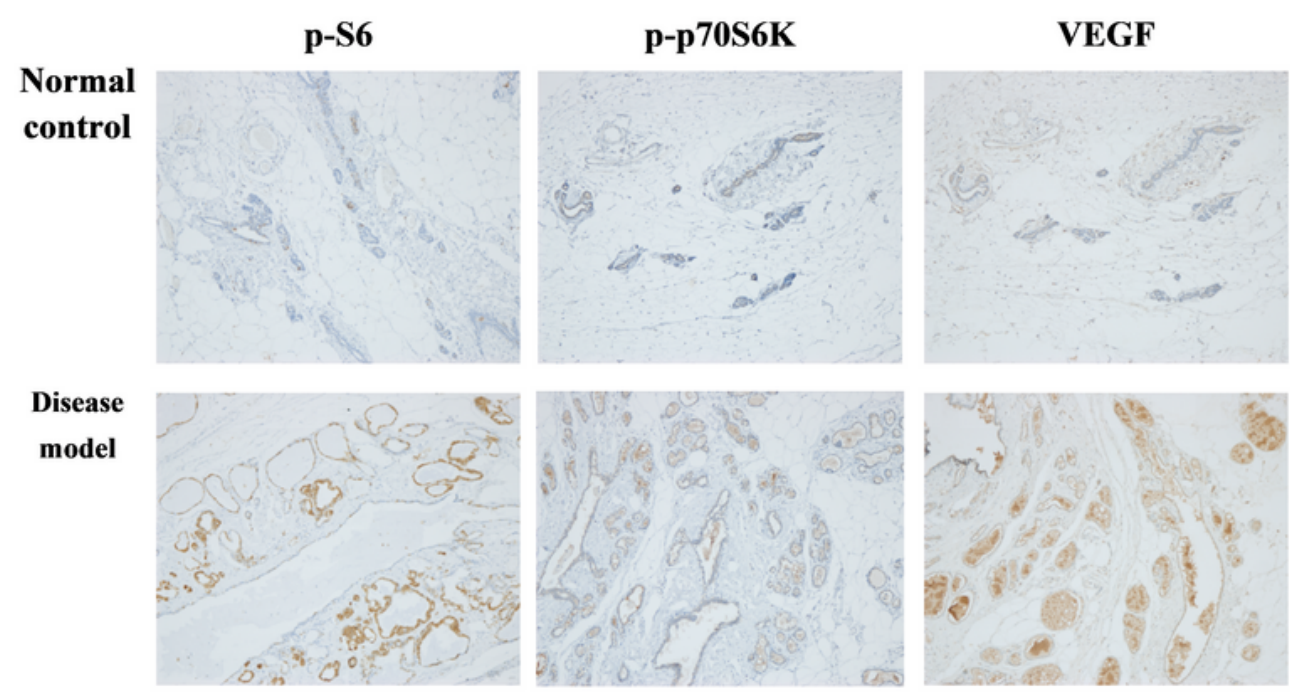

Tamoxifen
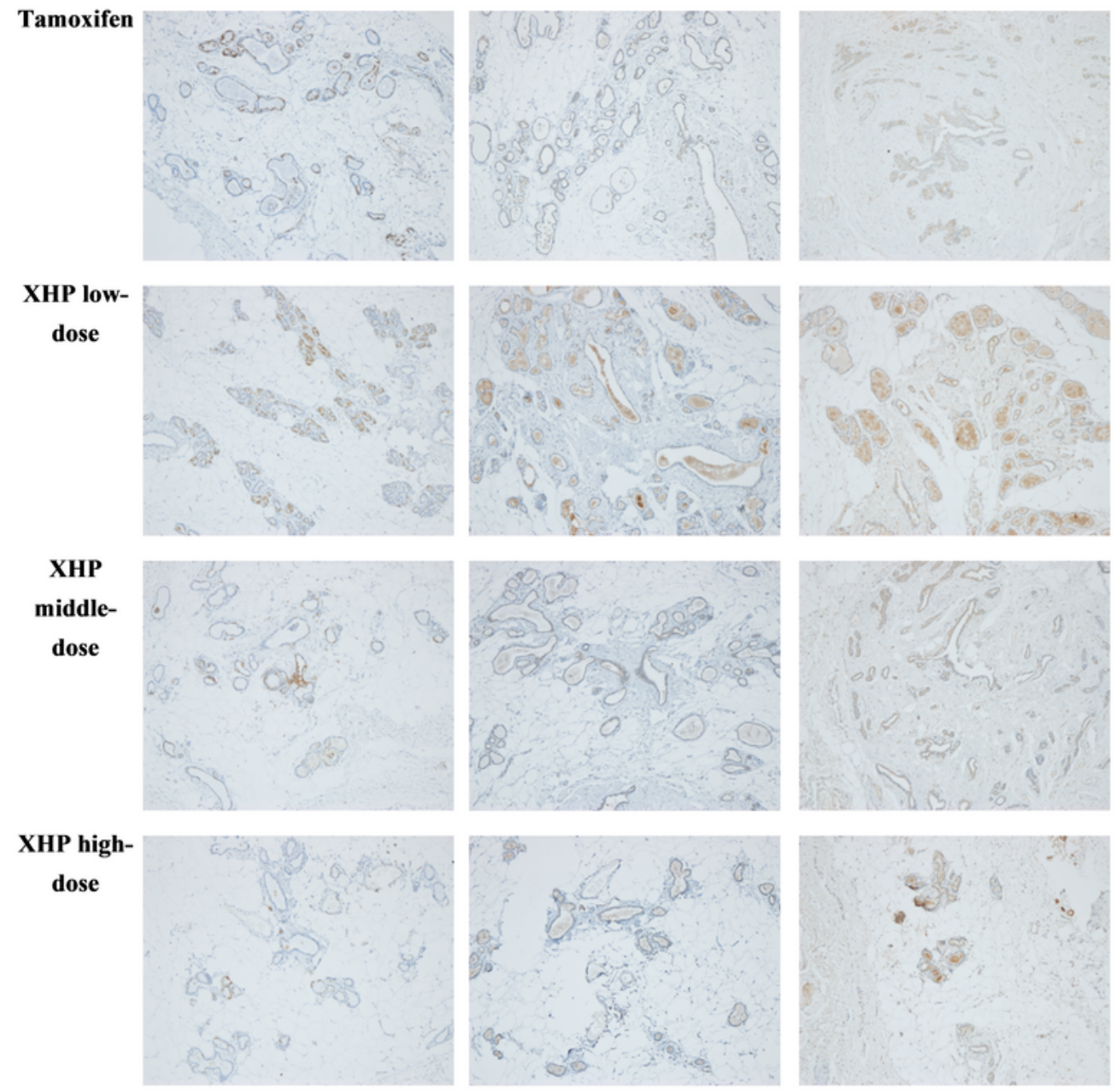

Figure 7

Protein expression of p-S6, p-p70S6K and VEGF in the breast tissue of rats in each group $(\mathrm{IHC}, \times 100)$. 


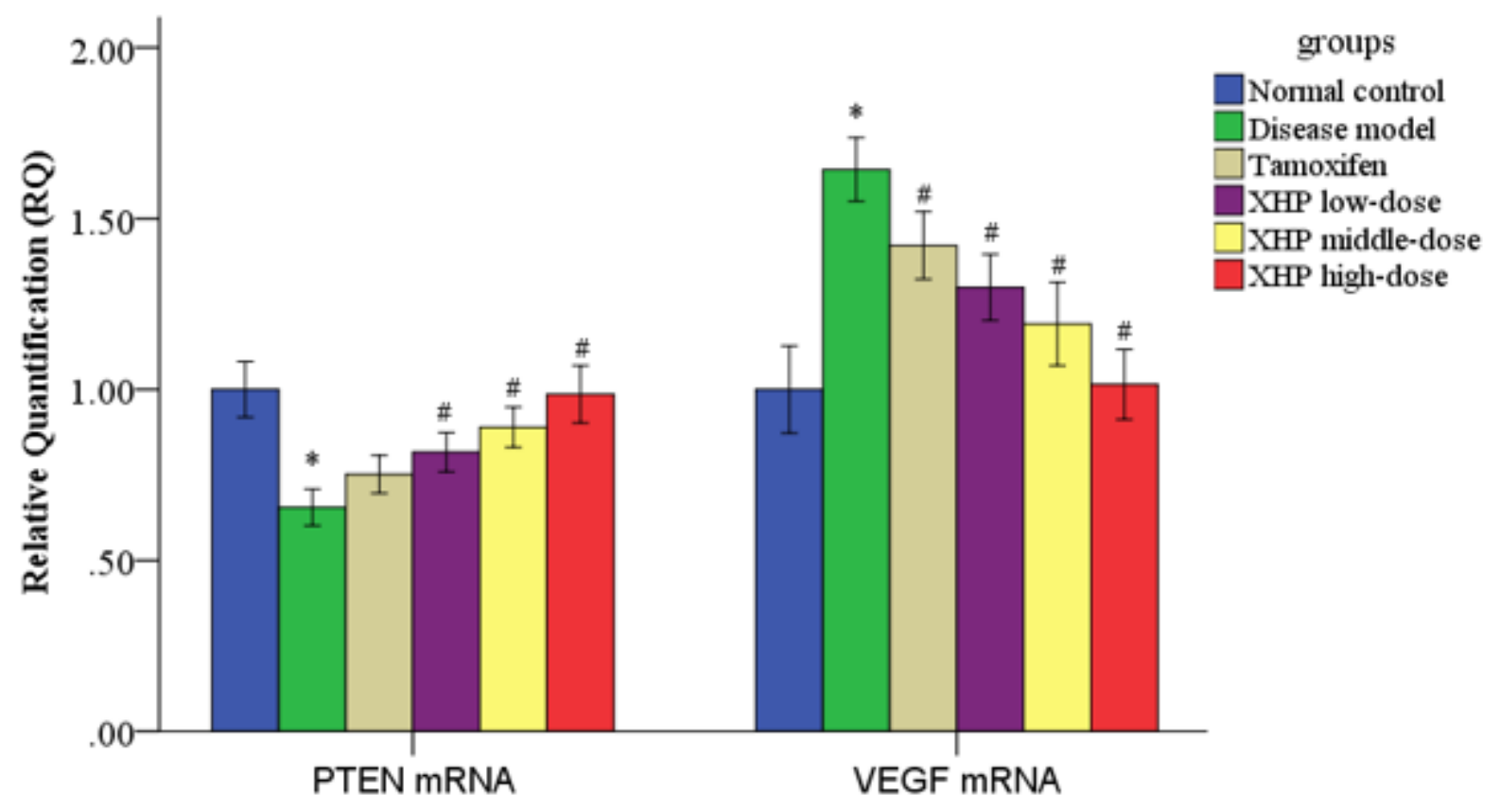

Figure 8

Relative expression levels of PTEN mRNA and VEGF mRNA in breast tissue of rats in each group 